The Journal of Animal \& Plant Sciences, 30(5): 2020, Page: 1098-1105

ISSN (print): 1018-7081; ISSN (online): 2309-8694

\title{
POSTHATCH DEVELOPMENT IN RESPONSE TO BRANCHED-CHAIN AMINO ACIDS BLEND SUPPLEMENTATION IN THE DIET FOR TURKEY POULTS SUBJECTED TO EARLY OR DELAYED FEEDING
}

\author{
C. Kop-Bozbay ${ }^{1}$ and N. Ocak ${ }^{2 *}$ \\ ${ }^{1}$ Department of Animal Science, Faculty of Agriculture, Eskisehir Osmangazi University, 26480 Eskisehir, Turkey; \\ ${ }^{2}$ Department of Animal Science, Faculty of Agriculture, Ondokuz Mayis University, 55139, Samsun, Turkey \\ *Corresponding author's e-mail: nuhocak@omu.edu.tr
}

\begin{abstract}
Branched-chain amino acids (BCAA) have the potential to promote muscle formation and development in turkeys. A 7-d study was conducted to investigate the effect of a BCAA blend (3 L-leucine:1 L-isoleucine:2 L-valine) on growth performance, yolk sac weight and development of gut and skeletal muscles in turkey poults subjected to delayed feedings. In total, 288 newly hatched poults were allocated into 6 treatment groups in a 3 feeding regimes (FR) and 2 BCAA levels (BCAAL) in completely randomized design under factorial arrangement. Feeding regimes were: immediately feeding and watering (IF), $48 \mathrm{~h}$ (WF48) or $72 \mathrm{~h}$ (WF72) delay in feeding and watering, and BCAAL was diet with supplementation of 0 (0BCAA) and $2 \mathrm{~g}$ BCAA (2BCAA) blend per $\mathrm{kg}$. The WF48 and WF72 treatments decreased growth performance and ventriculus and jejunum weights compared to treatment IF. Treatment IF and WF48 increased pectoralis muscle (PM) weight compared to treatment WF72. Weight gain tended to be higher in the 2BCAA poults. 2BCAA increased ventriculus and PM weights but decreased gut length compared to 0BCAA. 2BCAA increased the feed intake of the WF48 poults compared to the WF72 poults. In conclusion, the BCAA blend promoted posthatch development by enhancing PM in the poults subjected to delayed feedings.
\end{abstract}

Key words: poultry, posthatch feeding, amino acid, yolk utilization, organ development.

https://doi.org/10.36899/JAPS.2020.5.0125

Published online June 25, 2020

\section{INTRODUCTION}

In the poultry industry, hatchlings are withheld feed and water up to $72 \mathrm{~h}$ depending on the time or distance from hatchery to rearing farms. This period or distance is contributing to the body weight loss associated with the development of gastrointestinal tract (gut), some organs and muscles, and thus, meat yield at market age (Mozdziak et al., 2002; Halevy et al., 2003). Therefore, early posthatch period is one of the critical periods for weight gain, developmental programming of digestive and metabolic organs, and skeletal muscles in poultry, including turkeys (Mozdziak et al., 2002).

Studies performed to reduce the negative effect of off-feed time and water showed that the use of some specific supplements such as amino acids of egg protein (Tabeidian et al., 2011) or amino acid blend (Sklan and Noy, 2003a; Wylie et al., 2003; Nierobisz et al., 2007) or $\beta$-hydroxy- $\beta$-methylbutyrate (HMB, Moore et al., 2005) as well as starter diet (Mozdziak et al., 2002; Sklan and Noy, 2003a) are necessary in early posthatch period. Leucine, isoleucine and valine known as the branchedchain amino acids (BCAA), make up about one-third of muscle protein and promote muscle formation and development. Therefore, some studies have focused on the effect of limitation of isoleucine and valine in diets based on maize and soybean meal (Corzo et al., 2009, 2010) or valine and isoleucine (Berres et al., 2010a, b; Miranda et al., 2014, 2015; Ospina- Rojas et al., 2014, 2019) fortification of a low-protein diet for broilers during starter and grower phases. Valine and isoleucine are considered the $4^{\text {th }}$ limiting amino acid in diets with reduced protein content (Corzo et al., 2009, 2010; Berres et al., 2010a). Ospina-Rojas et al. (2014) noted that the combined supplementation of valine and isoleucine is required to improve the poultry performance and the breast meat yield. It has been indicated that among BCAA, only leucine is capable of activating translation initiation factors and stimulating protein synthesis in skeletal muscles (Tavernari et al., 2013; Ospina-Rojas et al., 2019).

There has been no information on effects of the blend of BCAA in starter diet on the yolk utilization, the growth performance and development of the gut and skeletal muscles. Therefore, it was hypothesized that when adding a BCAA (3 L-leucine:1 L-isoleucine:2 Lvaline) blend to diet would improve growth performance and muscle formation in the turkey poults subjected to delayed feeding. To test this hypothesis, there feeding regimes (no delay, $48 \mathrm{~h}$ delay and $72 \mathrm{~h}$ delay) were assessed with two BCAA blend supplementations $(0$ or 2 g BCAA blend) in starter diet with respect to growth performance and weights of residual yolk sac, the full gut 
and its segments, metabolic organs and skeletal muscle at $7^{\text {th }}$ day of age.

\section{MATERIALS AND METHODS}

Birds, experimental design and housing: An experiment was conducted at the Research Farm of Ondokuz Mayis University. Turkey (Hybrid Converter) eggs were obtained from a commercial company (Cuddy Farm, Karabuk, Turkey) and were incubated at the Poultry Unit in the Research Farm. At the $24^{\text {th }}$ day of incubation, after infertile eggs were removed, all eggs were transferred to hatching baskets. The incubation procedure was applied following the Hybrid Converter manual. To avoid prolonged fasting period and potential dehydration, hatching baskets were examined every $5 \mathrm{~h}$, and newly hatched chick just after clearing its shell (defined as time of hatch) was weighed and hatching time was recorded. To reduce variability in the delay in time to feed and water access within one batch of poults, 288 poults with similar weight from each hatching baskets were transferred immediately to floor pens in a temperature-controlled poultry room. Then, newly hatched turkey poults were allocated randomly into six experimental groups in $3 \times 2$ factorial completely randomized design ( 3 feeding regimes, FR $\times 2 \mathrm{BCAA}$ levels, BCAAL). The FR treatments were immediately feeding and watering (no delay, IF), $48 \mathrm{~h}$ delay in feeding and watering (WF48) and $72 \mathrm{~h}$ delay in feeding and watering (WF72), and BCAAL were 0 (0BCAA) and $2 \mathrm{~g}$ BCAA blend supplementation (2BCAA) per $\mathrm{kg}$ diet with 4 replicates each included 12 birds. The birds in the IF group were provided feed and water within $4 \mathrm{~h}$ of hatching (Moore et al. 2005). The BCAA blend used in this study were mixed within ratio of 3 L-leucine (Cas no: 61-90-5): 1 L-isoleucine (Cas no: 72-18-4): 2 L-valine (Cas no: 73-32-5). Thus, 2 g BCAA blend contained starter diet included up to about $1 \mathrm{~g}$ L-leucine per $\mathrm{kg}$, which it was equal the HMB of $1 \%$ in a previous study (Moore et al. 2005). During the experiment (one week), poults on the IF treatment were fed on starter diet and water ad libitum, whereas WF48 and WF72 birds were held in the transfer boxes for 48 and $72 \mathrm{~h}$, respectively, without access to feed and water, then, allowed to access feed and water.

Poults were distributed into 24 floor pens ( 4 pen per treatment and 12 birds per pen) for 7 days. Each of the pens $(1.5 \times 1.75 \mathrm{~m})$ was furnished with $5 \mathrm{~cm}$ of wood shavings as litter, and equipped with a 125 watt bulb heat lamp, an automatic drinker and a red circular poultry feeder plate. Ambient temperature was maintained at 32 $\pm 1^{\circ} \mathrm{C}$ with $60-70 \%$ relative humidity by using a thermostatically controlled heater and natural ventilation. The experiment was performed at the similar management practices, except feeding time and diet (Table 1), taking into account the all requirements recommended in management guide for Hybrid Converter turkey.

Measurements: To determine body weight, feed intake and feed conversion ratio ( $\mathrm{g}$ feed: $\mathrm{g}$ gain), poults and feed were weighed using an electronic scale with 0.01 sensitivity at $7^{\text {th }}$ day of age. Mortality was recorded daily during the experimental period ( 1 to 7 days of age). At the end of the experiment, two birds (one female and one male) from each replicate (eight birds per treatment or totally 48 poults) were slaughtered humanly to determine weights of yolk sac, full gut, proventriculus, empty gizzard (ventriculus), pancreas, small intestine segments such as duodenum, jejunum and ileum. Yolk sac, heart, liver, and full gut were carefully removed from the abdominal cavity, and pancreas was properly separated from the digestive tract, and then they were weighed. The full gut and the small intestine segments (duodenum, jejunum and ileum individually separated) were measured in length and recorded. All these processes were done as described by Maiorka et al. (2003) and Tabeidian et al. (2011). The pectoralis and iliotibialis muscles were weighed and recorded (Li and Velleman, 2009). Relative weights and lengths (when appropriate) of the yolk sac, organs and muscles were calculated as percentages of body weight ( $\mathrm{g}$ or $\mathrm{cm} / 100 \mathrm{~g}$ body weight). The total mortality of each pen was divided by the number of poults in each pen at the beginning of the trial and multiplied by 100 .

Statistical analyses: Analyses of variance were carried out using the GLM procedure of SPSS (Windows version of SPSS, release 21.0, SPSS Inc., Chicago, IL, USA) to evaluate the effect of FR, BCAAL and FR $\times$ BCAAL interaction on posthatch growth, yolk utilization and development of some organs in turkey poults. Pen means were used as the experimental unit for all analyses. Data regarding mortality, relative organ weights and lengths were subjected to arcsine $\sqrt{ } \%$ transformation. The significant differences were compared using Tukey's range test. Differences between treatments were considered to be significant when $P \leq 0.05$ and tended to be significant when $0.05 \leq P \leq 0.10$.

\section{RESULTS}

Body weight gain and feed intake (98.8 and $124.0 \mathrm{~g} /$ poult $)$ of the IF poults were higher $(P<0.001)$ than those of the WF48 (113.6 and $85.7 \mathrm{~g} /$ poult) and WF72 (89.6 and $82.3 \mathrm{~g} /$ poult) poults, while feed conversion ratio of the IF and WF48 (1.12 and 1.32 vs. 1.09) poults was higher $(P=0.005)$ than those of the WF72 poults (Table 2 ). The WF72 poults consumed less feed than the WF48 poults $(P<0.001)$. Body weight gain until 7 days of age tended to be higher in the 2BCAA poults compared to the 0BCAA group (86.6 vs. 91.2 $\mathrm{g} /$ poult, $P=0.085)$, but it had not got any significant effect 
on feed intake and feed conversion ratio (Table 2). The FR $(1.04 \%$ for all FR treatments, SE=1.041) and BCAAL ( $1.39 \%$ for $0 \mathrm{BCAA}$ and $0.69 \%$ for $2 \mathrm{BCAA}, \mathrm{SE}=0.850)$ treatments did not affect mortality rates. The FR $\times$ BCAAL interaction was detected for feed intake $(\mathrm{P}=0.042)$. The 2BCAA treatment increased the feed intake of the WF48 poults but decreased that of the WF72 poults.

The yolk sac weights of poults in the IF group were lower $(P=0.032)$ than those of poults in the WF48 group (0.04 vs. $0.22 \mathrm{~g} / 100 \mathrm{~g}$ body weight, Table 3$)$. The IF poults had higher proventriculus $(P<0.001)$, ventriculus $(P<0.001)$ and jejunum $(P=0.069)$ weights (0.86, 4.64 and $3.17 \mathrm{~g} / 100 \mathrm{~g}$ body weight, respectively) compared to the WF48 $(0.78,3.80$ and $3.21 \mathrm{~g} / 100 \mathrm{~g}$ body weight) and WF72 poults $(0.72,3.66$ and $2.92 \mathrm{~g} / 100 \mathrm{~g}$ body weight). Proventriculus weight of the WF72 poults was lower $(P<0.001)$ than those of the WF48 poults. The 2BCAA treatment increased proventriculus ( 0.75 vs. 0.82 $\mathrm{g} / 100 \mathrm{~g}$ body weight, $\mathrm{P}=0.001)$ and ventriculus (3.48 vs. $3.89 \mathrm{~g} / 100 \mathrm{~g}$ body weight, $P=0.012$ ) weights compared to the 0BCAA group. The 2BCAA treatment decreased duodenum (2.54 vs. $2.39 \mathrm{~g} / 100 \mathrm{~g}$ body weight, $\mathrm{P}=0.012$ ) weights compared to the 0BCAA group. Lengths of the full gut $(P<0.001)$, duodenum $(\mathrm{P}=0.001)$ and jejunum $(\mathrm{P}=0.001)$ from the IF poults $(89.6,12.6$ and $30.2 \mathrm{~cm} / 100$ g body weight, respectively) were lower than those from the WF48 (97.7, 13.7 and $32.8 \mathrm{~cm} / 100 \mathrm{~g}$ body weight, respectively) and the WF72 $(99.9,14.2$ and $34.0 \mathrm{~cm} / 100$ $\mathrm{g}$ body weight, respectively) poults. The ileum length $(32.2 \mathrm{~cm} / 100 \mathrm{~g}$ body weight) of the WF72 poults was higher $(P=0.003)$ than those $(28.5 \mathrm{~cm} / 100 \mathrm{~g}$ body weight $)$ of the IF poults. The 2BCAA treatment decreased full gut (100.4 vs. $91.1 \mathrm{~cm} / 100 \mathrm{~g}$ body weight, $P<0.001)$, duodenum (14.1 vs. $13.0, P=0.001)$, jejunum (33.7 vs. 31.0, $P=0.001)$ and ileum (31.7 vs. $29.5, P=0.014)$ lengths compared to the OBCAA treatment.

Table 4 shows that the IF poults had lower $(P=0.002)$ liver weight compared to WF48 and WF72 poults (3.35 vs. 4.03 and $3.88 \mathrm{~g} / 100 \mathrm{~g}$ body weight). The weights of pectoralis $(P=0.024)$ and iliotibialis $(P<0.001)$ muscles of the IF (2.72 and $4.03 \mathrm{~g} / 100 \mathrm{~g}$ body weight, respectively) and WF48 (2.67 and $4.48 \mathrm{~g} / 100 \mathrm{~g}$ body weight) poults were higher compared to WF72 (2.47 and $3.74 \mathrm{~g} / 100 \mathrm{~g}$ body weight) poults. The iliotibialis muscle weight of the IF poults was lower $(P<0.001)$ than those of WF48 poults. Supplemental BCAA blend increased liver (3.66 vs. $3.84 \mathrm{~g} / 100 \mathrm{~g}$ body weight, $P=0.019$ ), pancreas ( 0.24 vs. $0.30, \mathrm{P}=0.004)$ and pectoralis muscle (2.54 vs. $2.70, P=0.046)$ weights. There was the interaction effect of FR $\times$ BCAAL on the liver weight $(P=0.058)$.

Table 1. Composition of the experimental diet (as-fed basis).

\begin{tabular}{|c|c|c|c|}
\hline \multicolumn{2}{|l|}{ Ingredients (g/kg) } & \multicolumn{2}{|c|}{ Calculated chemical composition (g/kg) } \\
\hline Maize & 476.4 & Metabolizable energy (MJ) & 12.0 \\
\hline Soybean meal (CP 44\%) & 331.0 & Crude protein & 239.4 \\
\hline Sunflower meal (CP 32\%) & 116.5 & Lysine & 13.1 \\
\hline Fish meal (CP 65\%) & 30.0 & Methionine & 4.2 \\
\hline Vegetable oil & 10.0 & Methionine + Cystine & 8.1 \\
\hline Limestone & 6.1 & Threonine & 9.5 \\
\hline Dicalcium phosphate, $18 \%$ & 2.6 .0 & Tryptophan & 3.0 \\
\hline Sodium chloride & 1.5 & Arginine & 17.2 \\
\hline \multirow[t]{7}{*}{ Vitamin-mineral premix ${ }^{1}$} & 2.5 & Histidine & 6.6 \\
\hline & & Phenylalanine & 12.2 \\
\hline & & Leucine $^{2}$ & $20.6(2.26)$ \\
\hline & & Isoleucine & $11.4(1.17)$ \\
\hline & & Valine & $12.7(1.34)$ \\
\hline & & Calcium & 10.0 \\
\hline & & Available phosphorus & 6.0 \\
\hline
\end{tabular}

${ }^{1}$ Supplied per kilogram of feed: Fe, 50 mg; Cu, 15 mg; Mn, 120 mg; Zn 100 mg; Co, 0.2 mg, I, 1.5 mg; Se, 0.3 mg; vitamin A (retinyl acetate), $12000 \mathrm{IU}$; cholecalciferol, $0.125 \mathrm{mg}$; vitamin E (DL-a-tocopheryl acetate), $100 \mathrm{mg}$; vitamin K3 (menadione), $4 \mathrm{mg}$; thiamine, $3 \mathrm{mg}$; riboflavin, $8 \mathrm{mg}$, pantothenic acid, $15 \mathrm{mg}$; niacin, $50 \mathrm{mg}$; pyridoxine, $4 \mathrm{mg}$; folic acid, $2 \mathrm{mg}$; cobalamin, $0.015 \mathrm{mg}$; Dbiotin, $0.25 \mathrm{mg}$; choline, $200 \mathrm{mg}$;

${ }^{2}$ Values in parentheses are the contents of starter diet with branched-chain amino acid blend (3 L-leucine:1 L-isoleucine:2 L-valine) at $2 \mathrm{~g} / \mathrm{kg}$. 
Table 2. The effects of delayed feeding regimes and branched-chain amino acids supplementation on body weight (g/poult), feed intake (g/poult), feed conversion ratio (g feed:g gain) and mortality (\%) in turkey poults 1 .

\begin{tabular}{|c|c|c|c|c|c|c|c|c|c|c|}
\hline & \multicolumn{2}{|c|}{ IF } & \multicolumn{2}{|c|}{ WF48 } & \multicolumn{2}{|c|}{ WF72 } & \multirow[b]{2}{*}{ SEM } & \multicolumn{3}{|c|}{ Main effects of } \\
\hline & OBCAA & 2BCAA & OBCAA & 2BCAA & OBCAA & 2BCAA & & FR & BCAAL & $\begin{array}{c}\text { FR } \times \\
\text { BCAAL }\end{array}$ \\
\hline $\begin{array}{l}\text { At hatch } \\
\text { Body weight } \\
\text { At } 7^{\text {th }} \text { day of age }\end{array}$ & 63.39 & 63.46 & 63.87 & 64.73 & 64.63 & 65.15 & 0.306 & & & \\
\hline Body weight & 95.34 & 102.25 & 84.09 & 87.39 & 80.46 & 84.08 & 1.580 & $<0.001$ & 0.085 & 0.814 \\
\hline Feed intake & 122.49 & 125.42 & 106.62 & 120.51 & 93.35 & 85.88 & 1.265 & $<0.001$ & 0.337 & 0.042 \\
\hline $\begin{array}{l}\text { Feed conversion } \\
\text { ratio }\end{array}$ & 1.28 & 1.23 & 1.27 & 1.38 & 1.16 & 1.02 & 0.025 & 0.005 & 0.696 & 0.155 \\
\hline Mortality & 0.00 & 2.08 & 2.08 & 0.00 & 2.08 & 0.00 & 0.601 & 0.415 & 0.571 & 0.288 \\
\hline
\end{tabular}

${ }^{1}$ Means represent four pens of 12 poults per treatment.

$\mathrm{IF}=$ immediately feeding and watering (no delay), WF48 $=48 \mathrm{~h}$ delay in feeding and watering, WF72 $=72 \mathrm{~h}$ delay in feeding and watering, 0BCAA $=0 \mathrm{~g}$ BCAA blend supplementation per $\mathrm{kg}$ diet, $2 \mathrm{BCAA}=2 \mathrm{~g} \mathrm{BCAA}$ blend supplementation per $\mathrm{kg}$ diet, $\mathrm{FR}=$ feeding regimes, $\mathrm{BCAAL}=$ the $\mathrm{BCAA}$ blend levels.

Table 3. The effects of delayed feeding regimes and branched-chain amino acids supplementation on the weights $\left(\mathrm{g} / 100 \mathrm{~g}\right.$ body weight) and lengths $\left(\mathrm{cm} / 100 \mathrm{~g}\right.$ body weight) of yolk sac gut and some segments in poults ${ }^{1}$.

\begin{tabular}{|c|c|c|c|c|c|c|c|c|c|c|}
\hline & \multicolumn{2}{|c|}{$\mathbf{I F}^{2}$} & \multicolumn{2}{|c|}{ WF48 } & \multicolumn{2}{|c|}{ WF72 } & \multirow[b]{2}{*}{ SEM } & \multicolumn{3}{|c|}{ Main effects of } \\
\hline & OBCAA & 2BCAA & OBCAA & 2BCAA & OBCAA & 2BCAA & & FR & BCAAL & $\begin{array}{c}\text { FR } \times \\
\text { BCAAL }\end{array}$ \\
\hline \multicolumn{11}{|l|}{ Weight of } \\
\hline Yolk sac & 0.02 & 0.05 & 0.16 & 0.33 & 0.11 & 0.12 & 0.031 & 0.032 & 0.307 & 0.491 \\
\hline Full gut & 6.97 & 16.83 & 16.67 & 16.97 & 15.58 & 15.62 & 0.279 & 0.117 & 0.909 & 0.951 \\
\hline Proventriculus & 0.81 & 0.90 & 0.74 & 0.81 & 0.69 & 0.74 & 0.010 & $<0.001$ & 0.001 & 0.702 \\
\hline Ventriculus & 4.48 & 4.79 & 3.66 & 3.94 & 3.52 & 3.80 & 0.056 & $<0.001$ & 0.012 & 0.993 \\
\hline Duodenum & 2.49 & 2.36 & 2.58 & 2.46 & 2.55 & 2.36 & 0.029 & 0.373 & 0.012 & 0.847 \\
\hline Jejunum & 3.23 & 3.12 & 3.27 & 3.15 & 3.06 & 2.77 & 0.055 & 0.069 & 0.121 & 0.769 \\
\hline Ileum & 2.73 & 2.56 & 2.64 & 2.48 & 2.58 & 2.46 & 0.058 & 0.654 & 0.196 & 0.979 \\
\hline \multicolumn{11}{|l|}{ Length of } \\
\hline Gut & 94.7 & 84.6 & 101.1 & 94.2 & 105.2 & 94.6 & 0.94 & $<0.001$ & $<0.001$ & 0.686 \\
\hline Duodenum & 13.3 & 11.9 & 14.1 & 13.3 & 14.8 & 13.6 & 0.16 & 0.001 & 0.001 & 0.723 \\
\hline Jejunum & 31.9 & 28.4 & 33.8 & 31.9 & 35.4 & 32.5 & 0.39 & 0.001 & 0.001 & 0.721 \\
\hline Ileum & 30.1 & 26.9 & 31.2 & 30.9 & 33.8 & 30.8 & 0.43 & 0.003 & 0.014 & 0.328 \\
\hline
\end{tabular}

${ }^{1}$ Means represent four pens of two poults per treatment.

${ }^{2}$ The abbreviations are as in Table 2.

Table 4. The effects of delayed feeding regimes and branched-chain amino acids supplementation on the weights (g/100 g body weight) of metabolic organs and skeletal muscles in poults ${ }^{1}$.

\begin{tabular}{|c|c|c|c|c|c|c|c|c|c|c|}
\hline & \multicolumn{2}{|c|}{ IF $^{2}$} & \multicolumn{2}{|c|}{ WF48 } & \multicolumn{2}{|c|}{ WF72 } & \multirow[b]{2}{*}{ SEM } & \multicolumn{3}{|c|}{ Main effects of } \\
\hline & ОВСАA & 2BCAA & OBCAA & 2BCAA & ОВСАA & 2BCAA & & FR & BCAAL & $\begin{array}{c}\text { FR } \times \\
\text { BCAAL } \\
\end{array}$ \\
\hline Heart & 0.67 & 0.70 & 0.66 & 0.70 & 0.70 & 0.64 & 0.009 & 0.857 & 0.240 & 0.803 \\
\hline Liver & 3.32 & 3.37 & 3.88 & 4.17 & 3.78 & 3.98 & 0.075 & 0.002 & 0.019 & 0.058 \\
\hline Pancreas & 0.24 & 0.30 & 0.26 & 0.35 & 0.24 & 0.26 & 0.010 & 0.120 & 0.004 & 0.443 \\
\hline Pectoralis muscles & 2.59 & 2.85 & 2.59 & 2.74 & 2.45 & 2.50 & 0.037 & 0.024 & 0.046 & 0.504 \\
\hline Iliotibialis muscles & 4.12 & 3.95 & 4.41 & 4.55 & 3.64 & 3.84 & 0.046 & $<0.001$ & 0.555 & 0.261 \\
\hline
\end{tabular}

${ }^{1}$ Means represent four pens of two poults per treatment.

${ }^{2}$ The abbreviations are as in Table 2.

\section{DISCUSSION}

The results of the present study indicated that delayed feeding for $48 \mathrm{~h}$ or $72 \mathrm{~h}$ without the blend of
BCAA supplementation in starter diet resulted in decreased body weight and feed intake in poults compared to IF (no delay in feeding and watering) and 2BCAA birds. Therefore, the supplementation of the BCAA blend was relatively adequate to get rid of the 
adverse effects of delayed feeding on the performance and physical characteristics of some organs and skeletal muscle of turkey poults. The extra growth rates (21.4, 12.1 and $19.6 \%$ for IF, WF42 and WF72 poults) by the BCAA bland supplementation may remain through marketing, as reported by Sklan and Noy (2003a). However, the duration of the present study is not sufficient to argue that the results can be extrapolated to marketing age. Because the mortality was within the accepted limit for all groups, the deaths was not associated with any specific treatment. The posthatch development of poults in the present study was quite below standards of commercial poults due to diets with further refined protein. This was related to the fact that amino acid supplementation of diets has not always resulted in bird performance comparable with that of birds fed high-protein diets (Berres et al., 2010b).

Our results on body weight and feed intake indicate that the BCAA blend supplementation may allow formulating diet having lower protein content than that of standard starter diets, by $3 \%$ and, especially, delayed feeding for $48 \mathrm{~h}$ without compromising the performance of birds in the early posthatch period. The similar results have been obtained that dietary BCAA supplementation to low (Berres et al., 2010a, b; Miranda et al., 2014; Ospina-Rojas et al., 2014, 2019) or normal protein concentrations (Wylie et al., 2003; Corzo et al., 2009). The results on performance and digestive system support the idea that the supplementation of the amino acid blend in starter diet for poultry can improve growth performance by increasing the physical and functional development of the digestive system (Sklan and Noy, 2003a; Maiorka et al., 2003). Poults that withheld feed and water for 48 or $72 \mathrm{~h}$ were not successful to make compensatory growth due to a lower feed intake, although they had a lower feed conversion ratio, as reported in the previous studies (Halevy et al., 2003; Moore et al., 2005; Yang et al., 2009).

The results on posthatch growth support the idea that optimal broiler performance is dependent on the small number of limiting amino acids, particular for the young chick from 1 to 7 days of age (Berres et al., 2010b). However, if the dietary content of isoleucine is sufficient to meet the requirements of the broiler, relatively the excess amounts of leucine and valine do not depress growth (Ospina-Rojas et al., 2014). Wylie et al. (2003) reported that supplemental valine resulted in increased body and muscle weight. Berres et al. (2010b) reported that higher cumulative feed conversion ratio of broilers fed low-protein diets supplemented with valine + isoleucine was a result of poor performance from 1 to 7 days of age. Miranda et al. $(2014,2015)$ noted that if the goal is to reduce dietary protein, the useful results should be achieved by adding L-isoleucine with further reductions in protein if L-valine is, also, added. Indeed, Miranda et al. (2015) reported that broilers fed low- protein diet supplemented with L-Valine and LIsoleucine had similar performance results compared to those fed diets with high protein not supplemented with these AAs. The BCAA blend used in the present study was relatively efficacious in the optimization of the growth performance of poults at the early stages of life, because the L-Valine and L-Isoleucine levels required for the optimum performance may be probably higher (Ospina-Rojas et al., 2019). Accordingly, both the levels of leucine, isoleucine and valine supplied from the BCAA blend has no enough beneficial effect on feed intake and thus, feed conversion ratio or it was not such a level that would cause a beneficial effect on these variables. The impact of BCAA on weight gain may relate to the beneficial effect of HMB on weight gain and muscle development in turkey poults. Indeed, Moore et al. (2005) reported that HMB-fed poults had higher body weight than the control diet-fed poults. Based on these documents and our results, the mixture of BCAA could reduce not only the feed intake and feed costs (Miranda et al., 2014) involved in posthatch development but also the excretion of some nutrients, which has the potential for diminishing pollution problems associated with faecal nitrogen. Unfortunately, the nitrogen excreta were not investigated in the present study. This might be too important in later ages of poults since in early ages all animals use dietary nitrogen in amino acid or protein from more efficiently than older ones, as reported by Rivera-Torres et al. (2011).

The effect of FR on residual yolk sac in the present study was in agreement with the previous studies on poults (Noy et al., 2001) and chick (Yang et al., 2009). Therefore, the effect of FR $\times$ BCAAL interaction on feed intake may explain the fact that the WF48 birds had heavier residual yolk sac compared to other feeding regimes. Moreover, the amount of residual yolk sac and body gain during posthatch period are signs of the development of the gut and capability to maintain its nutritional requirements (Yang et al., 2009). This may explain why delayed feeding regimes and BCAA supplementation had different effects on the weights of yolk sac, gut and muscles, and subsequent growth performance in the newly hatched poults. A higher intestinal weight in poults receiving dietary BCAA indicates birds need higher amount of protein amount beside yolk proteins for furnishing their intestines. It is extremely important for the poults to consume nutrients just after hatching as much as possible to improve muscle development since the exogenous nutrients provided by the feed are complementary to the yolk nutrients (Bigot $e t$ al., 2003). Therefore, nutrition in the first posthatch days should take into account both the contribution of the yolk and the ability to utilize exogenous nutrients (Sklan and Noy, 2003a), especially the present dietary BCAA are already to be absorbed from intestine to be utilised for protein synthesis. 
The feed off time may cause retardation of development and overall maturation of digestive organs (Maiorka et al., 2003), because the yolk sac not only provides energy but also the necessary protein for intestine and muscle growth (Sklan and Noy, 2003a), as observed in the present study. A higher yolk sac weight in the poults that withheld feed and water for $48 \mathrm{~h}$ when compared to early feeding may be related to lower enzyme activity in the small intestine, morphological development of the intestine (Bigot et al., 2003; Sklan and Noy, 2003b) and relatively utilization of exogenous nutrients (Petek et al., 2011). Indeed, in the current study, the relative lengths of full gut and its segments were longer in delayed feeding for $48 \mathrm{~h}$ compared to early feeding. The results related to the gut weight indicate that in the presence or absence of any diet, the gut may develop, but in the presence of exogenous feed or nutrients such as BCAA, growth rates of gut and its segments were higher, as reported in a previous study (Sklan and Noy, 2003b).

The results on proventriculus, ventriculus and pancreas are agree with findings of Maiorka et al. (2003), who showed that a higher development in these organs was associated with a better feed efficiency and growth rate. A reduction in the weight and length of full gut due to delayed feeding depressed probably the digestion of feeds and absorption of nutrients (Pires et al. 2007), because of a reduction in area that required for digestion and absorption (Maiorka et al. 2003). In the present study, the ratios of gut weight to gut length for the IF, WF48 and WF72 groups were found as 0.19, 0.17 and 0.16 , respectively. However, Sklan and Noy (2003b) observed that in the posthatch poult intestinal surface area is not a limiting factor in growth, which was correlated with digestive secretions, fat and protein uptake. The impact of delayed feeding of starter diet for $72 \mathrm{~h}$ on growth rate of pancreas at the first $7 \mathrm{~d}$ posthatch may be insufficient to stimulate the development of pancreas with fully functioning, as evidenced the current lower growth rate of poults.

Early nutrition may affect skeletal muscle growth via its influence on satellite cell mitotic activity (Mozdziak et al., 2002; Halevy et al., 2003) in early posthatch periods. Thus, the positive impact of immediate access to diet and the BCAA blend may be attributed to increased liver and muscle glycogen reserves, muscle protein synthesis via physical and functional development of the intestinal tract (Yegani and Korver, 2008). A $48 \mathrm{~h}$ or $72 \mathrm{~h}$ feed deprived poults when fed on BCAA unsupplemented diet, pectoralis muscle and ventriculus weights decreased, and, consequently, reduction in body weight gain appeared, which might be related to the intensities of the presence of HMB and insulin-like growth factor 1 (IGF-1) since these metabolites can increase satellite cell number and mitotic activity (Halevy et al., 2003; Moore et al., 2005; Pedrosa et al., 2013) and thus, improve breast meat yield (Halevy et al., 2003; Moore et al., 2005). So, it can be said that high leucine level in our study led to higher HMB and IGF-1 contents in the metabolic pool of poults fed with BCAA supplemented-diet and, then, helped the developmental programming of the muscle and digestive system in poults as supported by Ostaszewski et al. (2000). Unfortunately, we did not investigate these metabolites. The previously published studies (Corzo et al., 2009, 2010; Berres et al., 2010a, b; Miranda et al., 2014, 2015; Ospina-Rojas et al., 2014, 2019) and the present study outcome that the different results might be attributed not only in the poultry species and strains used, but also husbandry conditions, growing period and age of the birds, protein restriction, feeding regimes, and especially the BCAA contents of diets.

Conclusion: To conclude BCAA in low protein diet prevented body weight losses and accelerated muscle development in the early posthatch period. In early posthatch, delayed feeding regimes in poults fed on starter diet without BCAA supplementation resulted a poorer weight gain and lower feed intake than those of BCAA supplementation and fed immediately just after hatching. The dietary fortification of leucine and valine was relatively adequate to get rid of the adverse effects of delayed feeding on the growth performance and skeletal muscle development of turkey poults. The effects of dietary BCAA blend on metabolites such as HMB, IGF-1 and activation of signalling pathways related to programming of muscle development in newly hatched poultry should, also, be investigated. Furthermore, dietary quantity of protein and energy are, more likely, to be important in the assessment of responses to BCAA supplementation.

Acknowledgements: This study, a part of $\mathrm{PhD}$ project of first author, was approved by the local Ethical Committee of Ondokuz Mayis University for Experimental Animals and ascertained that this experiment is not an unnecessary repetition of previous experiments. The authors wish to thank the financial support from the Scientific Research Fund of Ondokuz Mayis University (PYO.ZRT. 1904.13.011), and Berk Yem Sanayi and Hasinoglu Tavuk Isletmesi.

Conflict of interest: No conflict of interests have been declared by the authors.

\section{REFERENCES}

Bigot, K., S. Mignon-Grasteu, M. Picard, and S. Tesseraud (2003). Effects of delayed feed intake on body intestine and muscle development in neonate broilers. Poult. Sci. 82: 781-788.

Berres, J., S.L. Vieira, M.T. Kidd, D. Taschetto, D.M. Freitas, R. Barros, and E.T. Nogueira (2010a). 
Supplementing L-valine and L-isoleucine in low-protein corn and soybean meal all-vegetable diets for broilers. J. Appl. Poult. Res. 19: 373379.

Berres, J., S.L. Vieira, W.A. Dozier III, M.E.M. Cortês, R. de Barros, E.T. Nogueira, and M. Kutschenko (2010b). Broiler responses to reduced-protein diets supplemented with valine, isoleucine, glycine, and glutamic acid. J. Appl. Poult. Res. 19: 68-79.

Corzo, A, R.E. Loar II, and M.T. Kidd (2009). Limitations of dietary isoleucine and valine in broiler chick diets. Poult. Sci. 88: 1934-1938.

Corzo, A, W.A. Dozier III, R.E. Loar II, M.T. Kidd, and P.B. Tillman (2010). Dietary limitation of isoleucine and valine in diets based on maize, soybean meal, and meat and bone meal for broiler chickens. Br. Poult. Sci. 51: 558-563.

Halevy, O, Y. Nadel, M. Barak, I. Rozenboin, and D. Sklan (2003). Early posthatch feeding stimulates satellite cell proliferation and skeletal muscle growth in turkey poults. J. Nutr. 133: 13761382.

Li, X., and S.G. Velleman (2009). Effect of transforming growth factor- $\beta 1$ on embryonic and posthatch muscle growth and development in normal and low score normal chicken. Poult. Sci. 88: 265275.

Maiorka, A, E. Santin, F. Dahlke, I.C. Boleli, R.L. Furlan, and M. Macari (2003). Posthatching water and feed deprivation affect the gastrointestinal tract and intestinal mucosa development of broiler chicks. J. Appl. Poult. Res. 12: 483-492.

Miranda, D.J.A., S.L. Vieira, C.R. Angel, H.V. Rios, A. Favero, and E.T. Nogueira (2014). Broiler responses to feeds formulated with or without minimum crude protein restrictions and using supplemental L-valine and L-isoleucine. J. Appl. Poult. Res. 23: 691-704.

Miranda, D.J.A., S.L. Vieira, A. Favero, C.R. Angel, C. Stefanello, and E.T. Nogueira (2015). Performance and meat production of broiler chickens fed diets formulated at different crude protein levels supplemented or not with L-valine and L-isoleucine. Anim. Feed Sci.Technol. 206: 39-47.

Moore, D.T., P.R. Ferket, and P.E. Mozdziak (2005). The effect of early nutrition on satellite cell dynamics in the young turkey. Poult. Sci. 84: 748-756.

Mozdziak, P.E., T.J. Walsh, and D.W. McCoy (2002). The effect of early posthatch nutrition on satellite cell mitotic activity. Poult. Sci. 81: 1703-1708.
Nierobisz, L.S., V. Felts, and P.E. Mozdziak (2007). The effect of early dietary amino acid levels on muscle satellite cell dynamics in turkeys. Comp. Biochem. Physiol. Part B, 148: 286-294.

Noy, Y., A. Geyra, and D. Sklan (2001). The effect of early feeding on growth and small intestine development in posthatch poult. Poult. Sci. 80: 912-919.

Ospina-Rojas, I.C., A.E. Murakami, C.R.A. Duarte, C. Eyng, C.A.L. Oliveira, and V. Janeiro (2014). Valine, isoleucine, arginine and glycine supplementation of low-protein diets for broiler chickens during the starter and grower phases. Br. Poult. Sci. 55: 766-773.

Ospina-Rojas, I.C., A.E. Murakami, C.R.A. Duarte, P.C. Pozza, R.M. Rossi, and E. Gasparino (2019). Performance, diameter of muscle fibers, and gene expression of mechanistic target of rapamycin in pectoralis major muscle of broilers supplemented with leucine and valine. Can. J. Anim. Sci. 99: 168-178.

Ostaszewski, P., S. Kostiuk, B. Balasinska, M. Jank, I. Papet, and F. Glomot (2000). The leucine metabolite 3-hydroxy-3-methylbutyrate (HMB) modifies protein turnover in muscles of laboratory rats and domestic chickens in vitro. $\mathrm{J}$. Anim. Physiol. Anim. Nutr. 84: 1-8.

Pedrosa, R.G., J. Donato Jr, I.S. Pires, and J. Tirapegui (2013). Leucine supplementation increases serum insulin-like growth factor 1 concentration and liver protein/RNA ratio in rats after a period of nutritional recovery. Appl. Physiol. Nutr. Metabol. 38: 694-697.

Petek, M., E. Yilmaz, and R. Cibik (2011). Effect of first feed intake time on broiler performance and carcass traits. J. Appl. Poult. Res. 32: 203-206.

Pires, D.L., E.B. Malheiros, and I.C. Boleli (2007). Influence of sex, age, and fasting on blood parameters and body, bursa, spleen and yolk sac weights of broiler chicks. Braz. J. Poult. Sci. 9: 221-228.

Rivera-Torres, V., J. Noblet, S. Dubois, and J. van Milgen (2011). Dynamics of energy utilization in male and female turkeys during growth. Animal. 5: 202-210.

Sklan, D. and Y. Noy (2003a). Crude protein and essential amino acid requirements in chicks during the first week posthatch. Br. Poult. Sci. 44: $266-274$

Sklan, D. and Y. Noy (2003b). Functional development and intestinal absorption in the young poult. Br. Poult. Sci. 44: 651-658.

Tavernari, F.C., G.R. Lelis, R.A. Vieira, H.S. Rostagno, L.F.T. Albino, and A.R. Oliveira Neto (2013). Valine needs in starting and growing Cobb (500) broilers. Poult. Sci. 92: 151-157. 
Tabeidian, S.A., A. Samie, J. Pourreza, and G. Sadeghi (2011). Effect of fasting or post-hatch diet's type on intestinal morphology in broilers. International Conference on Life Sci. Technol. 3: 69-74.

Wylie, L.M., G.W. Robertson, and P.M. Hocking (2003). Effects of dietary protein concentration and specific amino acids on body weight, body composition and feather growth in young turkeys. Br. Poult. Sci. 44: 75-87.

Yang, H., Z. Wang, S.L. Shi, L. Jian. and L. Wenzeng (2009). Effects of starter feeding time on body growth and viscera development of newly hatched chicks. Ital. J. Anim. Sci. 8: 585-593.

Yegani, M. and D.R. Korver (2008). Factors affecting intestinal health in poultry. Poult. Sci. 87: 20522063. 